\title{
Gobiernos locales en Europa Central y Oriental en una década de transformación
}

\section{Pawel Swianiewicz ${ }^{1}$}

La década de los años 90 trajo consigo cambios de gran importancia en el escenario político de la Europa Central y Oriental (ECO), y fue también una década en la que resurgió la democracia local en esta región. En este trabajo empezaremos con una discusión acerca de las variables en este contexto, escenario institucional de los gobiernos locales (en el que prestaremos especial atención a la posición que ocupan los líderes locales formales: los alcaldes) y la naturaleza de las relaciones central-local. Tras un largo periodo con un modo de gobernabilidad muy centralista y no democrático, el traspaso de poder y el fortalecimiento del gobierno local parecía ser el camino natural a seguir para muchos políticos. Pero ¿cuál es el modelo de gobierno local que ha surgido de estos cambios? ¿En qué medida las generalizaciones y las teorías utilizadas para describir los gobiernos locales y la democracia en las sociedades de Europa Occidental son útiles para comprender los procesos que se han llevado a cabo en la Europa Central y Oriental?

Después pasaremos a considerar la naturaleza de la gestión urbana. ¿Podemos decir acaso que las teorías occidentales de poder de la comunidad -tales como la teoría del régimen- son aplicables a la realidad de la Europa Central y Oriental (ECO)? $¿$ O quizás su validez queda limitada en gran parte al espacio político-geográfico? De forma similar, cabe preguntarse si el ampliamente discutido cambio de un gobierno local tradicional a una gobernanza local se puede asimismo apreciar también en los países ECO. ¿Son las ideas de la Nueva Gestión Pública ideas vivas y reconocidas allí o estamos hablando de tendencias cuya validez se limita en Europa a su parte occidental? CLARK $(1993,2000)$ parece sugerir la existencia de una convergencia global de prácticas de gestión en los gobiernos urbanos de varios países. Utiliza la etiqueta de Nueva Cultura Política para describir las nuevas tendencias en las diferentes regiones, incluyendo a las ciudades de ECO. ¿̨odemos coincidir con la propuesta de convergencia o estamos presenciando el nacimiento de un modelo institucional y de gestión distinto de los gobiernos locales en los países de $\mathrm{ECO}$ ?

Este trabajo trata de responder a estas cuestiones como intento inicial. Primero nos centraremos en la situación existente en diez países de ECO que son candidatos oficiales para la incorporación a la $\mathrm{UE}^{2}$, dejando a un lado a los países de la antigua Yugoslavia (con la excepción de Eslovenia) y la Unión Soviética (con la excepción de los Estados Bálticos), aunque también ilustraremos determinados aspectos de estos países.

\section{Escenario institucional de los Gobiernos locales en ECO}

Hay pocos modelos distintos de gobiernos locales europeos que se hayan distinguido en las investigaciones iniciales llevadas a cabo. Sin embargo, estas clasificaciones no incluyen a la Europa Central y Oriental. ¿Cómo encajan estos gobiernos locales de nueva creación en estas tipologías? ¿Es la situación tal que las democracias locales post-comunistas conforman un modelo separado (diferenciado)? ¿O quizás ellas (o algunas de éstas) son similares a alguno de los modelos previamente descritos por la literatura europea occidental? Existen varias publicaciones que incluyen descripciones de nuevos sistemas de gobierno local (ver por ejemplo: Coulson, 1995, Balderheim et al., 1996, Horvath, 2000, Kandeva, 2001). Pero dichas publicaciones 
bien se basan en etapas iniciales del desarrollo de los nuevos modelos (y por tanto sus conclusiones están en gran medida desfasadas) o bien se centran en una simple descripción sin ninguna intención de llegar a generalizaciones. Del mismo modo, análisis comparados de cambios en los gobiernos locales europeos publicados en los años 90 suelen dejar a un lado a los países postcomunistas $^{3}$. En este trabajo trataremos de contribuir a rellenar este hueco.

La información sobre los sistemas de gobierno local nuevos en los países de Europa Central y del Este se compara con las dos famosas clasificaciones de los modelos europeos occidentales, desarrolladas por PAGE/GoldSMITH (1987) y por SHARPE/HeSSE (1991). En su análisis de las relaciones central-local PAGE y GoLDSMITH (1987) distinguen claramente entre la Europa del Norte y la Europa del Sur. En su clasificación la Europa del Norte incluye a los países nórdicos, al igual que al Reino Unido ${ }^{4}$, mientras que la parte sur del continente está representada por Francia, España e Italia. El modelo de relaciones central-local se describe a través de tres dimensiones: (distribución de) funciones, discrecionalidad (de los gobiernos locales para adoptar decisiones con independencia de las políticas centrales) y acceso (de los gobiernos locales a la formulación de políticas centrales).

La clasificación de SHARPE y HESSE (1991) muestra multitud de similitudes con la clasificación desarrollada por PAGE y GOLDSMITH, aunque existen del mismo modo diferencias significativas. El primer modelo identificado por SHARPE y HeSSE se conoce como grupo Franco (modelo napoleónico), que podría identificarse con el modelo sur-europeo establecido por PAGE y GOLDSMITH. En este tipo el gobierno local disfruta de un estatus constitucional, pero, para la prestación de servicios, depende normalmente de la asistencia y dirección de las agencias centrales territorialmente desconcentradas (p. 606). El papel de los gobiernos locales es más un papel político que un papel funcional, la identidad de la comunidad tiene mayor relevancia que la prestación de servicios. También ponen de manifiesto la tendencia a "colonizar" el gobierno central por medio de nexos de partidos o cumul de mandats. Francia, Italia, Bélgica, España, Portugal y Grecia se clasifican dentro de este modelo.

El segundo modelo que identifican SHARPE y Hesse es el modelo típico para el Reino Unido e Irlanda. La diferencia principal respecto del modelo napoleónico es la existencia de un mayor grado de autonomía en lo que se refiere a las actividades del día a día. Los gobiernos locales carecen de una cláusula general de competencia.

El tercer modelo es el típico de Europa del Norte y Europa Central. Las relaciones central-local son similares a las del modelo anglosajón, pero hay un mayor énfasis en la democracia local. Al gobierno local se le otorga normalmente una competencia funcional general. Existen también normas procedimentales estrictas que rigen las relaciones intergubernamentales, un gran nivel de autonomía al igual que una independencia financiera. Se menciona a Escandinavia, Suiza, los Países Bajos y Alemania entre los países representantes de este modelo.

Ambos modelos se desarrollaron en los años 80 pero -como argumenta JoHN (2001: 39)- su validez se ha mantenido ${ }^{5}$ en su mayor parte. Además, JoHN aprecia que esta variación de los sistemas de gobierno local tiene consecuencias importantes para las transiciones del gobierno local a gobernanza local.

\subsection{Enfoque general de la reforma descentralizadora y la posición de los gobiernos locales en el ámbito de los Estados en vías de modernización}

Dirigiéndonos ya a la Europa Central y del Este, podemos apreciar que cualquier debate sobre gobierno local está fuertemente enraizado en la experiencia histórica de la centralización durante el periodo comunista. No es éste un fenómeno aislado -SHARPe/HeSSE (1991) aprecian que en España, Portugal, Austria o Alemania hay a menudo una identificación automática de la centralización con la autocracia, que no se da en los países anglosajones-. Está obviamente relacionada con la experiencia histórica anterior de estos países. En los países de la ECO también se produce una identificación automática de forma similar de la centralización con la autocracia que surge de la experiencia del Estado central comunista. En consecuencia, a menudo se considera la presencia de un gobierno local fuerte como un valor "por definición". Pero este amplio (o más bien vago) acuerdo verbal a favor de la descentralización apenas ha tenido como consecuencia una visión común del papel y la posición de los gobiernos locales. Como aprecian Petere/Zentai (2002: 5), "además [...] de los principios generales, apenas hubo ninguno consenso político respecto del modelo que incluye la arquitectura del Estado, y menos aún planes detallados para su establecimiento". Esta observación hace referencia a la falta de consenso dentro de los países individuales sometidos a reforma, y más aún pone de manifiesto la falta de una visión común en los diferentes países.

La diferencia más significativa entre los países se refiere a la decisión política de implementar la agenda de la descentralización. No en todas partes estaba el gobierno central igual de dispuesto a distribuir competencias en materia de servicios significativas a los municipios, ni tampoco era demasiado común renunciar al control férreo y directo sobre las políticas de las autoridades locales. Analizaremos ejemplos de estas diferencias más adelante en esta sección.

Los diferentes enfoques a la reforma descentralizadora en la Europa Central y del Este, pueden, con algo de simplificación, agruparse en los tres siguientes modelos (SWIANIEWICZ 2002b): 
(i) El enfoque paso a paso: en este caso las reformas fundamentales de los años noventa tienen su base en eventos anteriores. La desintegración política de 1989 y 1990 se encontró con sugerencias más o menos preparadas con antelación respecto de los cambios legales y económicos. Quizás Hungría, con su reforma económica que comenzó en los años 80, es el país que más se aproxime a este modelo

(ii) El salto adelante: en este caso no había tiempo para preparar o deliberar sobre nuevas leyes por adelantado. Sin embargo, los reformistas estaban decididos a introducir la descentralización de forma muy rápida. La reforma polaca de descentralización -en sus dos fases, implementada en 1990/1991 y 1998/1999- muestra probablemente la mayor parte de las características de este enfoque. Uno de los autores principales en materia de reformas de gobiernos locales polacos -Michael KULESZA- argumentaba que "la ventana para la reforma" estaba normalmente solo abierta durante un corto periodo de tiempo, y los que proponían cambios debían darse prisa antes de que la burocracia central tuviese suficiente fuerza de nuevo para bloquear la descentralización (KuLESZA, 2002)

(iii) El enfoque de que todo está ocurriendo demasiado rápido: se refiere a un cambio político muy rápido e inesperado. En este enfoque, la administración central estatal duda (o incluso se muestra reticente) a descentralizar el país: el principal argumento esgrimido es que los nuevos gobiernos locales no están preparados para aceptar nuevas responsabilidades y que una verdadera desconcentración de poder provocaría un caos político y una agitación económica. Durante la mayor parte de la reciente década dicho enfoque era típico de varios países de la región incluyendo entre ellos a Bulgaria, Rumania y a la mayor parte de los Estados formados en las antiguas Repúblicas Soviéticas. Se pueden encontrar ejemplos de este enfoque en Eslovaquia e incluso en la República Checa.

También Peteri/Zentai (2002) aprecian importantes diferencias entre las reformas del gobierno local en la región. Formulan la siguiente clasificación: (i) rápido comienzo, largo proceso (Polonia, Hungría); (ii) algún retraso seguido de reformas progresivas (Bulgaria, Letonia), (iii) comienzo tardío, esfuerzos para acelerar las reformas (Croacia, Eslovaquia).

¿Cuál es la situación actual resultante de las recientes reformas de descentralización? En primer lugar, es importante resaltar que el escenario institucional está todavía lejos de ser un escenario estable. La mayor parte de los países todavía buscan un modelo a largo plazo de gobiernos sub-nacionales. Muy recientemente Polonia, la República Checa y Eslovaquia implementaron nuevos niveles de gobierno (regional) -a finales de los años 90 o incluso a principios de esta década-. Pero aún no han finalizado las disquisiciones sobre su financiación (las normas actuales se tratan únicamente como normas de carácter temporal). En varios otros países se siguen cuestionando incluso aspectos básicos de las relaciones central-local y son aspectos de acalorado debate en los debates políticos actuales. Así que lo que apreciamos echando un vistazo a los escenarios actuales es una mera instantánea en el marco de una situación de rápidos cambios.

En la mayor parte de los países de la ECO los gobiernos locales disfrutan de una cláusula general de competencia, aunque en la práctica a menudo dicha cláusula se ve restringida por otras normas. Los gobiernos locales tienen también un status constitucional -la Constitución los menciona y protege (con algunas excepciones, como el caso de Letonia-). En Polonia la Constitución sólo menciona los municipios, mientras que la existencia de los demás niveles de gobierno depende completamente de las decisiones del Parlamento. Durante mucho tiempo en la República Checa se dio la situación contraria, en la que la Constitución mencionaba la existencia de regiones, pero dichas regiones no llegaron a existir antes del 2001. Existe incluso aún una situación similar en Eslovenia, donde la Constitución recoge tanto el nivel municipal como el nivel regional de autogobierno, pero solo el primero de éstos existe en la práctica. La posición constitucional del gobierno local es especialmente fuerte en el caso de Hungría, en el que cualquier modificación de una "Ley de Gobierno Local" orgánica requiere de la misma mayoría en el Parlamento como la mayoría requerida para reformar la Constitución Nacional.

\section{$1.2(\mathrm{Re}-)$ organización territorial}

Las diferencias entre los modelos de gobierno local de los países de la CEE se aprecian ya en su forma de enfrentarse a la organización territorial. Durante el periodo comunista la creencia extendida en las economías de escala, junto con el estilo autoritario de gobernanza, condujo a reformas masivas que favorecieron la fusión (amalgamation) en la mayor parte de los países de la región. La consolidación territorial se introdujo sin que se realizaran consultas reales a las comunidades locales. No sorprende por tanto, que la reacción natural frente a las primeras reformas en muchos países, fuera la de una fuerte presión de fragmentación de abajo a arriba ${ }^{6}$. Ello tuvo como consecuencia una extrema fragmentación de los gobiernos locales en la República Checa, Eslovaquia, Hungría y -en menor medida- en Letonia y Estonia. En Hungría el número de municipios se redujo de 3.021 en 1962 a 1.364 en 1988 para volver a 3.133 en 1992. En la República Checa el número de municipios se redujo de forma similar de 11.459 en 1950 a 4.104 en 1988 , pero después aumentó de nuevo hasta más de 6.000 a comienzos de los años 90. También fueron similares los cambios que se produjeron en 
Eslovaquia donde el número de gobiernos locales aumentó en más del 20\% (ver BALDERSHEIM et al, 1996). Asimismo, también se produjo una fragmentación territorial considerable en Croacia (Jurlina-AlibEGOVIC, 2002), en Albania (Mejora de la División Administrativa-Territorial, 2003) o en Macedonia donde el número de gobiernos locales aumentó de 34 a casi 150 (MAENPAA, 2002).

Pero dicha presión de fragmentación no se ha manifestado con la misma fuerza en algunos otros países. Las comunas polacas se fusionaron en 1973 y se redujeron de más de 4.000 a aproximadamente 2.400 , manteniendo un número relativamente estable hasta el momento (en la actualidad el número de gobiernos municipales es de 2.491). En Bulgaria la cantidad de municipios se redujo de 2.178 en 1949 a 255 a finales de los años 80 y siendo bastante similar al existente en la actualidad (SWIANIEWICZ, 2002c). En Lituania la reciente reforma territorial llevó a una importante consolidación territorial y a la creación de gobiernos municipales que son los segundos en mayor tamaño en Europa (después de los gobiernos locales del Reino Unido).

Como consecuencia de ello, junto con algunos países de la región en los que existen numerosos gobiernos locales pequeños ( mencionados arriba), también tenemos países con sistemas territoriales relativamente consolidados (Lituania, Bulgaria, Polonia y -en cierta medida- Eslovenia y Rumania). Tal y como refleja la tabla 1, el tamaño medio de los gobiernos locales municipales en la Europa Central y del Este difiere casi tanto como en la Europa Occidental.

Pero existe una característica común en la organización territorial en los países de la ECO. Dicha característica radica en la ausencia o debilidad ${ }^{7}$ de un nivel intermedio ("meso level") de gobierno elegido. Contraria a la tendencia en muchos países occidentales, en que los nuevos niveles de gobierno se han creado o fortalecido durante los últimos 20-30 años (SHARPE 1993), en los países de la ECO el nivel de gobierno situado por encima del nivel comunal se ha debilitado de forma significativa. La ausencia de un nivel de gobierno regional o por condados es quizás algo natural en algunos países pequeños, tales como los Estados Bálticos o Eslovenia. Pero también cabe apreciar el mismo fenómeno en países más grandes. En Bulgaria no existe un nivel de gobierno electo por debajo del gobierno nacional y por encima del nivel de gobierno municipal. En Hungría, se ha mantenido el nivel de gobierno de 19 condados (megye) -junto con 22 ciudades con los mismos derechos que los condados-, pero sus funciones y sus poderes se han visto seriamente debilitados si los comparamos con el periodo anterior. En Croacia el papel de 21 condados (zupanje) decreció de forma significativa hace unos años, cuando perdieron su poder de supervisión sobre otras ciudades (grad) y municipios rurales (obcina). En la actualidad, el presupuesto de los condados croatas es más de tres veces inferior al presupuesto de las ciudades y municipios. De forma similar, los condados rumanos (judete) tuvieron una posición importante hasta mediados de los años 90 , pero entonces perdieron gran parte de sus funciones, y en la actualidad sus recursos son menores que los de ciudades (orase) y comunidades rurales (comuna). Sin embargo, debería señalarse que los condados rumanos siguen jugando un papel muy importante en la toma de decisiones para la distribución de recursos entre los niveles inferiores de gobierno. En Polonia, la República Checa y Eslovaquia, la ola de reformas de 1990 sólo permitió el autogobierno local a nivel comunal. El gobierno a nivel de condado o regional electo tuvo que esperar hasta 1999 (creación de autogobiernos powiats y wojewodztwo en Polonia) o incluso hasta 2000 o 2002 (establecimiento de gobiernos kraj en Eslovakia y la República Checa). Más aún, incluso después del establecimiento de gobiernos de nivel intermedio, sus funciones son normalmente muy reducidas, su financiación depende en su mayor parte de transferencias del presupuesto central y bien no tienen papel alguno en la coordinación (o en influenciar) la actividad de los gobiernos de niveles inferiores, o si tienen algún papel en ello ese papel es muy limitado. La mayor parte de los servicios vitales junto con las competencias fiscales se han reservado con carácter general al nivel municipal (comunal) de autogobierno. Esto se ve reflejado en la figura, que muestra que la gran mayoría del gasto público sub-nacional pasa por el nivel de gobierno ciudad/municipio.

\begin{tabular}{|c|c|c|c|}
\hline País & $\begin{array}{c}\% \text { de municipios } \\
\text { por debajo de } 1.000 \\
\text { habitantes }\end{array}$ & $\begin{array}{c}\text { Población } \\
\text { media }\end{array}$ & $\begin{array}{c}\text { Área } \\
\text { media }(\mathrm{km} 2)\end{array}$ \\
\hline Inglaterra y Gales & 0 & 123.000 & 533 \\
\hline Lituania & 0 & 66.000 & 1,166 \\
\hline Bulgaria & 0 & 35.000 & 432 \\
\hline Suecia & 0 & 29.500 & 1,595 \\
\hline Países Bajos & 0.2 & 20.500 & 60 \\
\hline Dinamarca & 0 & 18.000 & 150 \\
\hline Polonia & 0 & 16.000 & 130 \\
\hline Eslovenia & 3 & 10.300 & 106 \\
\hline Finlandia & 5 & 10.500 & 730 \\
\hline Noruega & 4 & 9.000 & 710 \\
\hline Rumania & 2 & 7.600 & 81 \\
\hline Italia & 24 & 6.500 & 38 \\
\hline Estonia & 9 & 5.700 & 178 \\
\hline España & 61 & 5.000 & 60 \\
\hline Letonia & 32 & 4.300 & 115 \\
\hline Hungria & 54 & 3.300 & 32 \\
\hline Eslovaquia & 68 & 1.900 & 17 \\
\hline República Checa & 80 & 1.700 & 13 \\
\hline Francia & 77 & 1.300 & 15 \\
\hline
\end{tabular}

Nota: Los países de Europa Central y del Este se han resaltado en cursiva.

Fuente: Newton, KarRan (1985), Baldersheim et al. (1996), The Size of Municipalities..., (1995), HoRvaTH (2000), KANDEVA (2001). 
Los orígenes de la debilidad del nivel intermedio de gobierno se encuentran en la historia previa a 1990. Las regiones o condados ejercían un control directo sobre las municipios, y su posición de fortaleza se contemplaba casi como un sinónimo de la opresión a la autonomía local. De ahí se deriva que la reticencia a otorgar poderes significativos al nivel intermedio se debiera en su mayor parte al temor de los reformistas y de los políticos locales a que dicho nivel superior trataría aún de controlar a los gobiernos municipales.

Figura 1

Gasto Público Local como \% del PIB

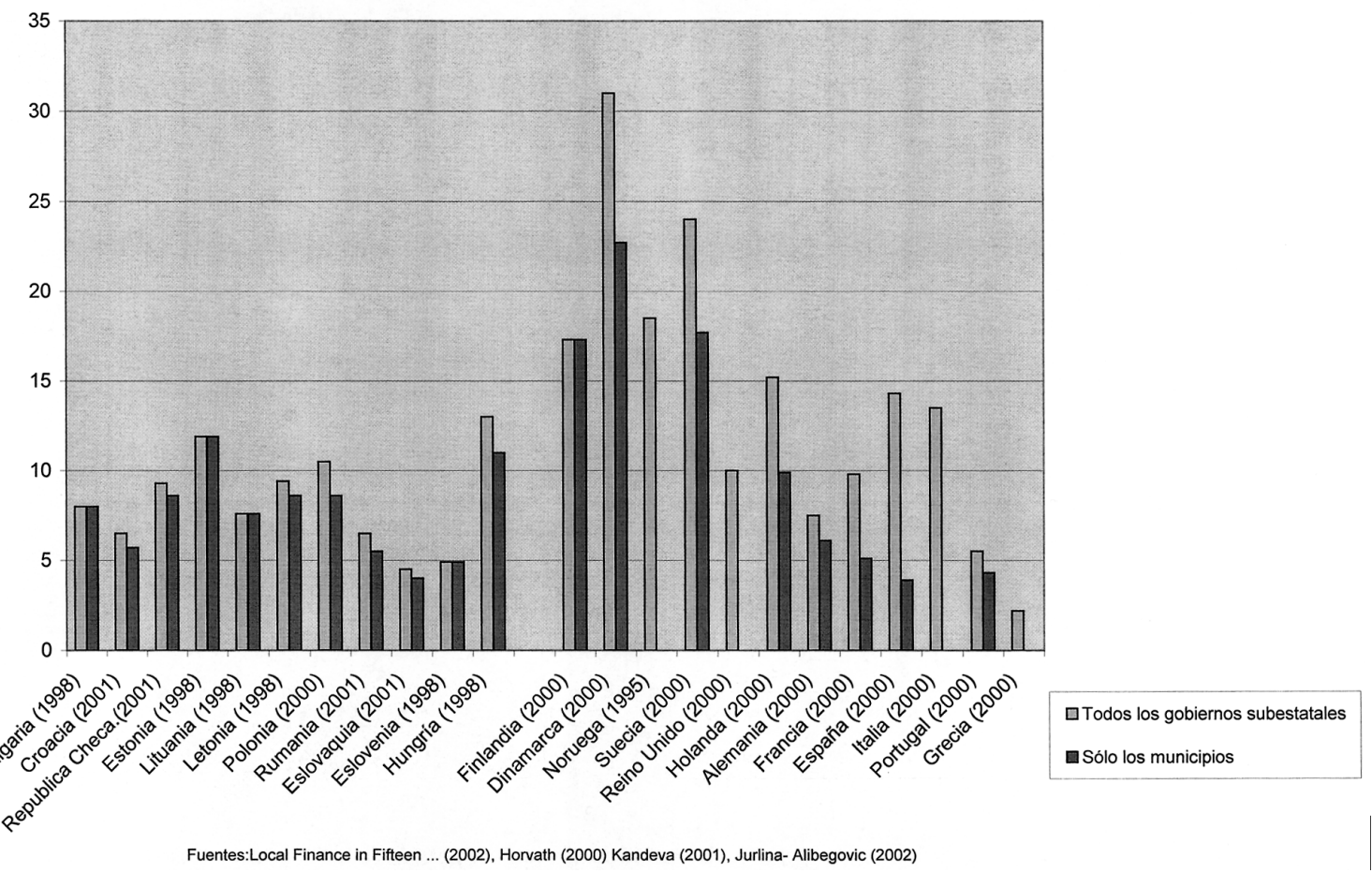

\subsection{Relaciones central-local}

Los datos proporcionados en la figura 1 también sugieren que -en términos de distribución de competencias- los países de Europa Central y del Este permanecen más centralizados que la mayor parte de los países de la parte norte de Europa Occidental. El porcentaje de gasto de los gobiernos sub-nacionales en PIB8 varía entre un 5\% en Eslovaquia y Eslovenia a ligeramente más del 10\% en Estonia, Hungría y Polonia. A menudo en la Europa del Noroeste, ese mismo porcentaje está por encima del 15\% (en los Países Bajos, Finlandia y Noruega) o incluso por encima del 20\% (en Suecia y Dinamarca).

La tendencia de los cambios no ha sido tampoco una tendencia uniforme por toda la región. El porcentaje de presupuestos sub-nacionales frente al PIB ha aumentado durante la última década en Estonia y Polonia, pero ha disminuido en Bulgaria, Lituania o Hungría. En la República Checa hemos observado en primer lugar una disminución gradual, pero recientemente también hemos observado un incremento en relación con el empuje de las reformas descentralizadoras. La tendencia no era clara o mostraba estabilidad en los restantes países de la región.

En contraposición con lo que PAGE y GolDSMITH (1987) apreciaron en Europa Occidental, no existe una estrecha correlación entre el tamaño de los presupuestos municipales y el nivel de población medio en la región de ECO. Existen países en los que el tamaño pequeño se corresponde con un bajo porcentaje de gasto municipal en relación con el PIB (Eslovaquia) y otros países en que el gran tamaño de los municipios coexiste con un porcentaje relativamente alto en relación con el PIB (Polonia). Pero tal y como muestran el caso húngaro y el caso de Estonia, podrían también existir algunos gobiernos locales pequeños que tuvieran un gasto muy grande al igual que grandes gobiernos que tuvieran presupuestos relativamente pequeños asignados (Lituania, Bulgaria). Parece que la decisión general de descentralizar ha sido más importante que el tamaño de la estructura.

Tal y como se mencionó con anterioridad, por un lado, la tendencia a una mayor autonomía local le parece a muchos reformistas como la adopción de una dirección intuitiva después de 
años de un sistema comunista extremadamente centralizado. Pero también existe una oposición a la descentralización de poderes, que en el caso de la Europa Central y del Este proviene típicamente de dos direcciones. En primer lugar, dicha oposición está relacionada con el temor de que demasiada autonomía de los gobiernos locales (y especialmente regionales) pueda dar lugar a la desintegración del país. Es fácil comprender este miedo, tras un periodo de nacionalismos "adormecidos" y de inexistencia formal de ninguna otra fuerza centrífuga. Un buen ejemplo de ello nos los proporciona Eslovaquia, donde algunos partidos políticos temen la autonomía de una minoría húngara. Cabe realizar apreciaciones similares en el caso de Rumania, Letonia, en el caso de Estados surgidos de las antiguas Repúblicas yugoslavas, o en el caso de Ucrania que teme dividirse entre el oeste que habla ucraniano y la parte este del país de habla rusa. Pero con menos sentido, se han formulado temores similares en países más homogéneos (desde un punto de vista étnico), tales como Polonia. La segunda fuente de temor frente a la descentralización está enraizada en la fuerte posición que ha ocupado de forma tradicional la burocracia del nivel central, que (con éxito) trata de proteger su fuerte posición. Una gran parte de la politización de la administración central proporciona fuerza adicional a las tendencias centralistas. Con cierto nivel de simplificación podemos valorar los índices de descentralización funcional como el resultado de una lucha política entre los reformistas a favor de la descentralización, por un lado, y la burocracia conservadora junto con los temores nacionalistas de la descentralización, por otro lado.

Dado que las otras dos dimensiones consideradas por PAGE y GOLDSMITH (1987) están relacionadas (discrecionalidad de los gobiernos locales para tomar decisiones de forma independiente respecto de la políticas centrales y acceso de los gobiernos locales a la formulación de las políticas centrales), la descripción completa de la posición actual de los gobiernos locales de los países de la ECO, requeriría estudios separados, ya que quedan fuera del ámbito de este trabajo. Sin embargo, cabe formular varias observaciones con carácter general. Así como en la Europa Occidental la discrecionalidad varía mucho de una función a otra quizás más que entre países. Sin embargo, hay algunos países -como es el caso de la República Checa, Hungría, Polonia, o Eslovaquia- que se aproximan más al modelo de "autonomía relativa" (tal y como lo define STOKER, 1991), mientras que algunos otros -tales como Rumania o Bulgaria- se aproximan más al modelo de agencia y a la directa intervención administrativa de los niveles superiores de gobierno en las actividades de los gobiernos locales. En ocasiones dichas intervenciones son de carácter informal, pero muchos líderes locales no son lo suficientemente fuertes como para oponerse a dichas intervenciones. La falta de criterios objetivos para la distribución de recursos (y/o los frecuentes cambios en estos criterios) también favorecen el ejercicio de un control estrictos sobre los gobiernos locales. Dicha distribución de recursos, basada a menudo en decisiones de carácter subjetivo adoptadas por la administración estatal, es frecuentemente un elemento del proceso de negociación más amplio. Pero también en el primero de los dos grupos de países (por ejemplo, en la República Checa, Hungría, Polonia y Eslovaquia), la limitación de forma directa de la discrecionalidad local es un fenómeno de considerable importancia. Se lleva a cabo en su mayor parte por medio de transferencias de recursos, que se distribuyen conforme a criterios que no siempre son transparentes. En Polonia, las concesiones específicas constituyen una parte relativamente modesta de los presupuestos municipales (alrededor del 18\%) pero en un condado y a nivel regional conforman casi la mitad de los ingresos totales.

El acceso a políticas centrales muestra mayores similitudes con el modelo que Page y GoldsMiTH (1987) identifican como modelo del sur de Europa. Las similitudes con el sistema francés de cumul des mandats no son algo excepcional en la Europa Central y del Este. En Polonia dicho sistema ha sido solo abolido recientemente. En las elecciones parlamentarias de 1997 salieron electos alrededor de 100 alcaldes y concejales como miembros del Parlamento (esto suponía casi un 25\% de todos los diputados electos ese año) y la mayoría de ellos mantuvieron sus puestos en los gobiernos locales de forma paralela a sus nuevas funciones en el legislativo central. Pero incluso después de eliminar el cumuls des mandats la actividad de lobbing (actividad de presión) de los parlamentarios de origen local a favor de decisiones individuales relativas a sus gobiernos locales es casi una regla. Sigue siendo bastante comun en Hungría y Eslovaquia tener el cargo de alcalde y ser miembro del Parlamento a la vez, aunque en el caso de Eslovaquia se critica mucho y se mantienen en la actualidad toda una serie de debates con respecto a prohibir la acumulación de puestos. En Rumania el sistema de cumul des mandats no está permitido, pero muchos alcaldes rumanos son figuras políticas poderosas y tienen una influencia considerable en la toma de decisiones a nivel central.

Esto no significa que el estilo de negociación del acceso esté completamente ausente. Las asociaciones de ciudades y comunas en la República Checa (SMOR), en Eslovaquia (ZMOS), en Bulgaria (NAMRB), al igual que numerosas otras asociaciones en Polonia y Hungría juegan un papel importante en las negociaciones con el gobierno central. En Polonia, donde se han creado asociaciones separadas por municipios rurales, pequeños pueblos, ciudades, ciudades metropolitanas y concejos existe una Comisión Gubernamental Conjunta Central-Local reconocida de forma oficial en la legislación nacional, en la que están representadas las principales asociaciones. En teoría, ninguna nueva normativa que pudiera tener un impacto en los gobiernos locales puede trasladarse al Parlamento sin haber sido discutida previamente en esta Comisión Conjunta. Pero los problemas con el funcionamiento de la Comisión y el bajo reconocimiento que se da a ésta en el día a día de la actividad del gobierno central, tiende a fortalecer la impresión de que un acceso directo y no oficial es más característico de la cultura política local. 
SHARPE y HeSSE (1991) manifiestan la variación en la actitud hacia los valores básicos de los gobiernos locales. En contraposición al modelo del Norte de Europa, en los Estados napoleónicos la función de la identidad local resulta ser más importante que el papel de ésta en relación con la eficiente prestación de servicios. También se da una variación de actitudes similar en el caso de los alcaldes centro-europeos. En un estudio de los alcaldes en Polonia, en la República Checa y en Eslovaquia se descubrió que los alcaldes polacos a la hora de pensar en el papel más importante que le correspondía a los gobiernos locales a menudo se centraban en la eficacia en la prestación de servicios, mientras que los alcaldes checos y especialmente los de Eslovaquia daban mayor importancia a la autonomía local y después a los valores democráticos (SWIANIEWCZ, 2003).

\subsection{Posición formal de los alcaldes (líderes de ciudades)}

Una de las características comunes de las reformas llevadas a cabo en la mayor parte de los países de la ECO ha sido la posición cambiante del alcalde del gobierno local. La existencia de un cargo formal del líder es esencial-este simple hecho es algo en lo que están de acuerdo aquellos que definen estilos de liderazgo primero y fundamentalmente por medio de la cultura política(por ejemplo, LEACH/WILSON, 2000: 13).

En los sistemas de gobierno local tradicionales, el papel fuerte de los líderes individuales (aunque -hasta hace pocoapenas fortalecidos por la elección popular y directa de alcaldes ejecutivos) se trató como una característica más típica del sur de Europa que del norte de Europa, donde con mayor frecuencia se podían encontrar más formas colectivas de liderazgo. Sin embargo, esta distinción tradicional se ha convertido recientemente en la "moda" más universal. LARSEN (2002) cita ejemplos de varios países europeos que se han decantado por reformas que llevan a la elección directa de los alcaldes. Hace poco se introdujo dicha elección directa de los alcaldes en todos los Länder alemanes, en la elección de alcalde del año 2000 en Londres también se iniciaron reformas similares en el Reino Unido, Italia comenzó su reforma en 1993, Irlanda planea llevar a cabo cambios similares para el año 2004 y 20 de los municipios noruegos experimentaron con elecciones directas de alcalde en 1999.

La misma tendencia se ha apreciado en la Europa Central y del Este. Así, se introdujeron elecciones directas de alcaldes a comienzos de los años 90 en Eslovaquia, Bulgaria, Rumania y Eslovenia, en 1994 en Hungría ${ }^{9}$ y muy recientemente (en 2002) en Polonia. De esta forma, sólo tres Estados bálticos y la República Checa siguen confiando todavía en un sistema en el que el alcalde es elegido por el consejo o en un sistema en el que se utilizan más formas colectivas de liderazgo ${ }^{10}$.
Sin embargo, el cargo de los alcaldes electos directamente varía de un país a otro. La tabla 2 resume brevemente estas diferencias. La primera observación a realizar es que, en contraposición con más recientes reformas llevadas a cabo en el sur de Europa, el alcalde no siempre obtiene una mayoría en el consejo. Esto puede conducir, y de hecho a menudo conduce a problemas serios de gestión cuando el alcalde se debe enfrentar con una oposición que ostenta la mayoría en el consejo. Si recordamos la baja estabilidad y el alto nivel de fragmentación de los partidos políticos en los países de la ECO, podemos esperar que haya numerosos casos en los que la adopción efectiva de decisiones sea difícil. Entre las 42 ciudades polacas con una población por encima de los 100.000 habitantes, sólo 7 alcaldes tiene un claro apoyo de las mayoría de los concejales. En la mayor parte de los supuestos restantes el/ella necesita recurrir a y confiar en coaliciones más o menos estables. En cinco ciudades la situación es aún más complicada- la mayoría del consejo la ostenta un grupo que está claramente en oposición con el alcalde, (SWIANIEWCZ/KLIMSKA, 2003). También se ha informado de la existencia de problemas similares en otros países, y a menudo dichos problemas se refieren a ciudades principales, como en el caso de la capital de RumaniaBucarest, o la capital de Albania- Tirana.

Existe una gran diferencia entre el cargo de un alcalde en Hungría y en el resto de los países analizados. Un alcalde húngaro, aunque es elegido directamente por los ciudadanos, no tiene funciones ejecutivas y su cargo se asemeja más al cargo de los alcaldes noruegos en aquellas ciudades que han estado experimentando recientemente con elecciones directas. En el resto de los países el alcalde tiene pleno poder ejecutivo. Pero el nivel de discrecionalidad a la hora de adoptar importantes decisiones personales y de carácter organizativo varía. En todos los países ya analizados queda bajo la responsabilidad del alcalde remitir una propuesta de presupuesto al consejo. Los concejales pueden introducir los cambios que prefieran a dicha propuesta, y que a su vez el alcalde no puede vetar (con algunas excepciones, como en el caso de Polonia, en que el alcalde puede disentir frente a la sugerencia de que se incrementen los préstamos concedidos a la ciudad).

Mouritzen/Svara (2002) definen cuatro tipos de liderazgo ideal: un alcalde con una posición fuerte, un líder de comité, un líder colectivo, y un gestor del consejo. ¿Cabe identificar la situación existente en los países de la ECO con algunos de estos modelos? En cierta medida sí. En la República Checa, en donde las funciones ejecutivas las ejercita el consejo, la situación se aproximaría más a la forma colectiva de liderazgo (la situación fue prácticamente idéntica en Polonia antes del 2002). Los Estados bálticos, en los que el alcalde se nombra por el consejo no se alejan tampoco de este modelo. Hungría, país en el que el consejo tiene un papel muy fuerte y la mayor parte de las funciones ejecutivas corresponden a los Altos Funcionarios (CEOs), no se aparta de la forma de consejo-gestor, aunque la elección direc- 
ta de un alcalde y su papel más que ceremonial supone una desviación del modelo ideal. La situación en Bulgaria, Polonia, Eslovaquia y Rumania resulta más difícil de clasificar. Sin duda, se aproxima al sistema de alcalde con posición fuerte, pero la falta de control de la mayoría del Consejo es una diferencia importante que hace que difiera de la descripción proporcionada por MOURITZEN y SVARA. Dicha descripción se refiere a las limitacio- nes existentes a la hora de contratar o despedir a personas claves en la administración (tal como el tesorero de la ciudad en Polonia o vice-alcalde en Bulgaria). Quizás cabría denominar a esta forma "alcalde fuerte y fuerte control por el consejo" (se aproxima más a un "liderazgo compartido" próxima a la formulación de GeTIMIS/GRIGORIADOU).

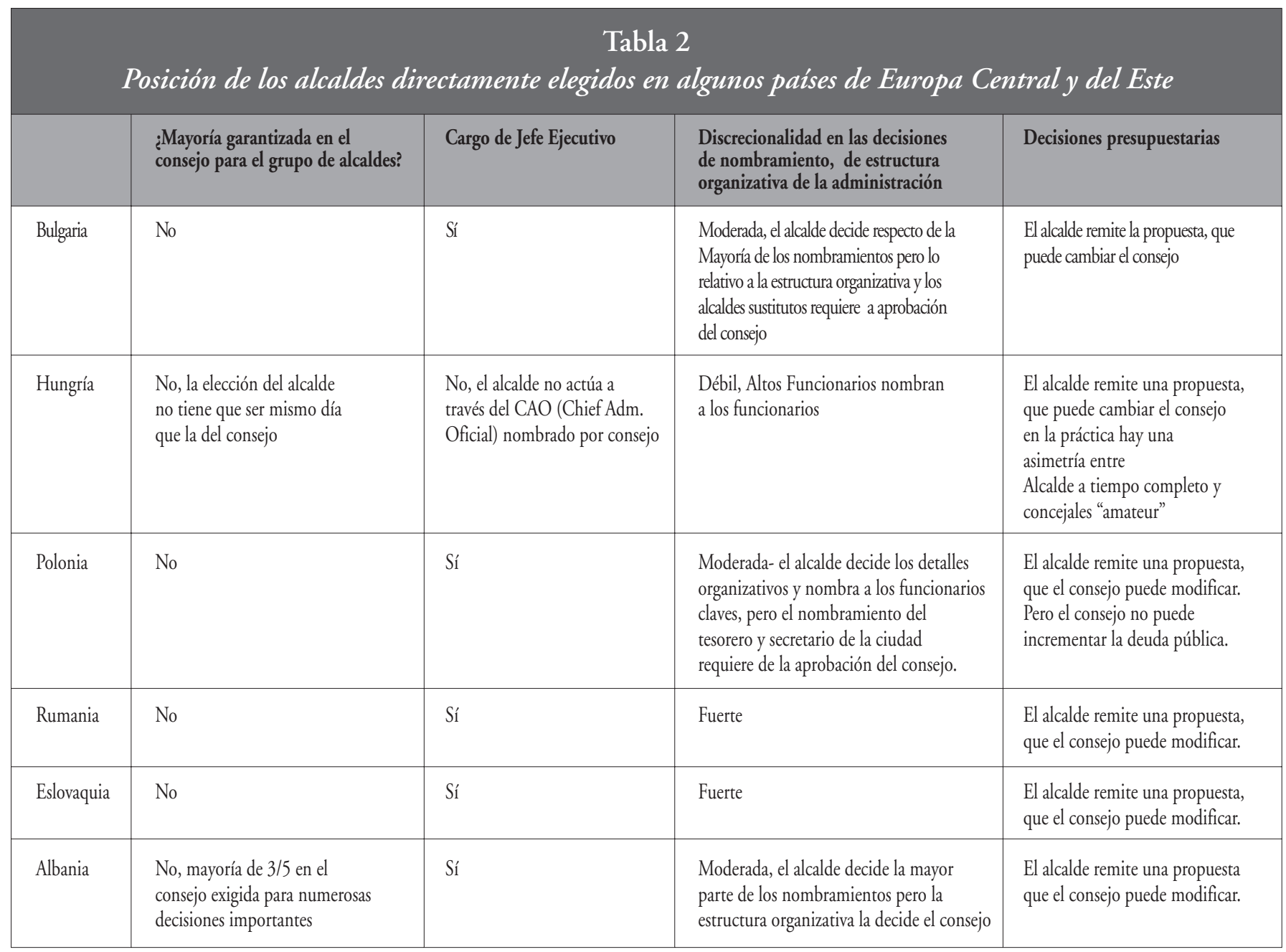

\subsection{Escenario institucional - resumen}

La tabla 3 resume brevemente los aspectos más característicos de los sistemas de gobierno local en Europa Central y del Este. Las conclusiones de esta sección se pueden resumir en lo siguientes elementos:

- A la hora de analizar el escenario de los gobiernos locales en Europa Central y del Este estamos hablando de un sistema sometido a continuos y sucesivos cambios. Por ello, sólo podemos analizar la situación actual en el momento presente, pero todavía no podemos estar seguros de cuál podría ser la situación después de los próximos años.
- Definitivamente, no existe un modelo común de gobierno local para todos (o al menos para la mayor parte) de los países de la región. Existe un alto nivel de variación en lo que se refiere a la organización territorial, la distribución de funciones, el nivel de discrecionalidad local y en lo que se refiere a los valores que se asocian con el gobierno local en varios países.

- Sin embargo, sí existen determinados aspectos característicos que resultan comunes para la mayor parte de los países de la región, como por ejemplo: niveles intermedios de gobiernos electos débiles o inexistentes, frecuentes 
contactos clientelísticos entre el gobierno central y el gobierno local. Existe también una creciente tendencia a adoptar modelos de gobierno local que se basan en la elección directa y popular de los alcaldes (sin embargo, esta tendencia todavía no incluye a los Estados bálticos ni a la República Checa). En la mayor parte de los casos el alcalde electo de forma directa es un jefe ejecutivo (Hungría es el único país que proporciona una excepción a esta regla).
- Algunos países de la Europa Central y del Este muestran tener mayores similitudes con el modelo del norte de Europa de gobiernos locales (Estonia, Polonia), mientras que en el caso de algunos otros países las situación que se asemeja más al modelo del sur de Europa (napoleónico) (Eslovaquia, quizás Bulgaria y Rumania). Pero la posición de los gobiernos locales de los países del centro de Europa no puede simplemente identificarse con alguno de los tipos descritos en el análisis llevado a cabo respecto de Europa Occidental.

\begin{tabular}{|c|c|c|c|c|c|c|}
\hline \multicolumn{7}{|c|}{ Tabla 3} \\
\hline & $\begin{array}{l}\text { Posición } \\
\text { constitucional }\end{array}$ & $\begin{array}{l}\text { No de niveles de } \\
\text { gobiernos locales } \\
\text { electos }\end{array}$ & $\begin{array}{l}\text { Fragmentación } \\
\text { territorial a nivel } \\
\text { municipal }\end{array}$ & $\begin{array}{l}\text { Alcalde ejecutivo } \\
\text { elegido directamente }\end{array}$ & $\begin{array}{l}\text { Ámbito de } \\
\text { descentralización } \\
\text { funcional }\end{array}$ & $\begin{array}{l}\text { Modo dominante } \\
\text { de ejercer control sobre } \\
\text { gobiernos locales }\end{array}$ \\
\hline Estonia & Sí & 1 & Sí & № & Amplio & \\
\hline Letonia & No & $1^{* *}$ & Sí & No & Reducido & \\
\hline Lituania & Sí & 1 & No & No & Reducido & \\
\hline Polonia & Sí & 3 & No & Sí & Amplio & \\
\hline República Checa & Sí & 2 & Sí & No & Reducido & \\
\hline Eslovaquia & Sí & 2 & Sí & $\mathrm{Si}$ & Reducido & \\
\hline Hungría & $\mathrm{Si}^{*}$ & 2 & Sí & $\mathrm{Si}^{* * *}$ & Amplio & \\
\hline Rumania & Sí & 2 & Sí & Sí & Reducido & admin.. \\
\hline Bulgaria & Sí & 1 & No & Sí & Reducido & admin. \\
\hline Eslovenia & Sí & 1 & No & Sí & Reducido & admin. \\
\hline
\end{tabular}

* Amplio definido como que supera el 10\% del PIB gastado por los gobiernos locales

** Mas un nivel superior de gobierno con un consejo elegido de forma indirecta

*** Se requiere mayoría constitucional para cambiar la Ley de Gobierno Local

**** El alcalde húngaro es elegido directamente pero no tiene poderes ejecutivos, que ostenta el CAO nombrado por el consejo.

\section{2. ¿Están acaso las ciudades de los países de la ECO transitando de un gobierno local a una gobernanza local?}

¿Cabe decir que los cambios en la gestión observados a menudo en los gobiernos locales de la Europa Occidental también se han visto reflejados en tendencias de carácter similar en la Europa Central y del Este? ${ }^{11}$. Dicha hipótesis es probable, dada la importante actividad llevada a cabo por los expertos en gobierno local extranjeros (financiado bien por la UE o por medio de programas bilaterales tales como USAID, el Fondo Británico de Know-How, etc.) Aunque el impacto de los consultores extranjeros en el esce- nario institucional de los nuevos sistemas de gobierno local en ECO ha sido muy limitado ${ }^{12}$, su influencia en los estilos de gestión de los líderes locales ha sido más visible.

Las recientes tendencias que resultan ser muy populares en varios países de Europa Occidental a menudo se resumen en un cambio de un gobierno local a un concepto más amplio de gobernanza local y a la introducción de una nueva gestión pública. Hambleton $(1998,2001)$ define el cambio hacia la gobernanza local como un cambio de una perspectiva que considera al gobierno local simplemente como un vehículo que proporciona un abanico de servicios públicos importante a una perspectiva que da un nuevo énfasis al liderazgo comunitario. La gobernanza implica procesos de influenciar y negociar con un amplio abanico de agencias del sector público y del sector privado para alcanzar los resultados queridos. JONEs (2001: 9) define la gobernanza como "un patrón flexible de toma de decisiones públicas basado en redes flexibles de individuos". Esto incluye la cooperación con una variedad de actores, incluyendo Organizaciones No Gubernamentales (ONGs) y organizaciones de intereses al igual que implica combinar recursos públicos y privados en los progra- 
mas de desarrollo. JONES enumera también un número de factores que en la práctica han catalizado el cambio de gobierno a gobernanza, como por ejemplo:

- la internacionalización de los gobiernos sub-nacionales;

- la privatización, y la contratación externa de los servicios;

- la adaptación de las técnicas de gestión conocidas como Nueva Gestión Pública.

¿Ha ocurrido algo de todo esto en los gobiernos locales de los países de la ECO? Debemos recordar que en Polonia el 78\% de los concejales y más del 90\% de los alcaldes eran recién llegados -sin experiencia previa en políticas locales y administración (SWIANIEWCZ, 2002d). El número de ellos en otros países de la región era algo menor, pero también significativamente altos: en Eslovaquia los concejales sin experiencia previa constituían en 1990 tanto como el 74\% de los representantes locales electos, en la República Checa el número correspondiente era del $71 \%$ y en Hungría del 60\% (BALDERSHEIM et al., 1996). Del mismo modo el clima económico en el que debían operar era también en gran medida nuevo. No resulta por tanto sorprendentemente que los nuevos políticos y administradores necesitaran buscar nuevas inspiraciones y soluciones. De esta forma, las ideas traídas por los consultores occidentales que venían a Europa Central y del Este, encontraban a menudo un buen caldo de cultivo ${ }^{13}$. Tal y como trataré de demostrar en las siguientes secciones, numerosos elementos que se incluyen en la definición de gobernanza de Hambleton o Jones -al igual que factores que se mencionan como factores que facilitan la gobernanza- pueden encontrarse en la práctica de la gestión local de ECO.

\subsection{Gobiernos locales y el desarrollo económico local.}

El interés de los alcaldes locales y de los concejales de los países de ECO no se limita ni mucho menos a una lista reducida de funciones municipales obligatorias. La mayor parte de los gobiernos locales no ven su papel como un simple papel de prestadores de servicios sino que se sienten responsables del bienestar general de las comunidades gobernadas. En un estudio dirigido en 1991 en la República Checa, Hungría, Polonia y Eslovaquia tanto los alcaldes locales como los concejales mencionaron el "desarrollo económico", la "creación de nuevos puestos de trabajo" y el "lidiar con el desempleo" como aquellas tareas que se situaban entre las más importantes para las autoridades locales. Esto era especialmente cierto respecto de los encuestados de Hungría y Eslovaquia, mientras que apenas se percibía en el caso de los políticos locales checos (BALDERSHEIM et al., 1996: 169-170). Estas jerarquías se han visto confirmadas por posteriores estudios de candidatos polacos en las elecciones locales de 1994 y en el estudio de 1997 sobre los alcaldes de la República Checa, Polonia y Eslovaquia ${ }^{14}$. Como podemos observar en la tabla 4, el crecimiento económico a largo plazo está entre la mayor parte de las prioridades para los alcaldes checos y polacos. Los polacos y -en menor medida- los líderes locales checos y eslovacos creen que los contactos diarios con los empresarios locales son muy importantes en el trabajo diario. Sin embargo, los polacos (en contraposición en cierta medida con sus colegas checos y eslovacos) no consideran que necesiten mayores competencias formales relacionadas con el desarrollo económico. Consideran que pueden confiar en la red de cooperación más que en una autoridad formal. Los alcaldes de los grandes gobiernos locales prestan atención al desarrollo económico mucho más a menudo que sus colegas de otras comunidades pequeñas ${ }^{15}$.

\begin{tabular}{|l|l|l|l|l|l|l|}
\hline \multicolumn{7}{|c|}{ Tabla 4} \\
Opiniones de los alcaldes sobre la importancia de los aspectos de desarrollo económico en las \\
actividades de los gobiernos locales
\end{tabular}


¿Pueden las políticas económicas locales existentes en la Europa post-comunista interpretarse a la luz de la teoría del régimen? Ya se ha llevado a cabo un intento de este tipo por SAGAN (2000) que analiza "regímenes" en algunas ciudades polacas. Comienza con la observación de que nos estamos enfrentando con ciudades en transición, en las que varios actores tratan de encontrar su lugar en los nuevos regímenes que se están formando. Los empresarios locales son a menudo actores dominantes. SAGAN presta una especial atención al capital extranjero -la mayor parte de las ciudades están muy necesitadas de nuevas inversiones, y esta situación permite que empresas extranjeras jueguen un papel muy importante en estos regímenes de nueva formación. Además de las observaciones realizadas por SAGAN, cabría añadir dos nuevos actores que juegan un papel muy importante en las políticas de muchas ciudades polacas: propietarios de pequeños comercios al por menor (y sus asociaciones) y consejeros de empresas constructoras (a menudo privatizadas, con anterioridad empresas públicas) que pujan en subasta por la implementación de los proyectos mayores de infraestructuras de desarrollo. A estas empresas no solo le interesan contratos ganadores (y a menudo utilizan sus contratos informales para mejorar sus posibilidades en las subastas públicas), sino que también juegan un papel activo a la hora de influenciar las políticas de las ciudades en una forma que incremente el número de proyectos que se puedan conseguir mediante subasta.

SAGAN defiende que la posición del gobierno local en el crecimiento contemporáneo de las coaliciones es relativamente débil. Esta situación se debe a la debilidad financiera de los gobiernos de las ciudades y también a la dramática exigencia de mayores recursos. La consecuencia de todo ello es una posición dominante de los negocios. Este argumento de SAGAN requiere definitivamente de una mayor verificación, pero se debería apreciar que las observaciones de SAGAN se oponen a los resultados de los estudios reputacionales sobre el poder en una comunidad (community power studies). En el proyecto estudio de LDI de 1991 (BALDERSHEIM et al., 1996), ninguno de los grupos de actores entrevistados ${ }^{16}$ mencionaron a los negocios o empresas locales como los grupos con mayor influencia a la hora de la adopción de decisiones a nivel local. Lo mismo sucede, si dejamos fuera a las pequeñas ciudades o a las comunidades rurales (con una población por debajo de los 30.000 habitantes). Esta situación se mantuvo sin cambios en el segundo proyecto estudio de LDI (en esta ocasión limitado únicamente a los alcaldes locales), que se llevó a cabo en 1997. Pero cabe resaltar que fueron fundamentalmente políticos locales entrevistados en estas encuestas -sus respuestas pueden no ser del todo ciertas o sinceras; cabe esperar que tiendan a sobrevalorar su propia influencia y a infravalorar ligeramente de forma ingenua (¿o cínica?) el impacto de los grupos de presión externos (incluyendo los negocios) en su propio comportamiento.
SAGAN aprecia también un aspecto específico de los regímenes políticos seguido en varios ciudades de mediano tamaño y pequeñas -a menudo se trata a los acontecimientos culturales como importantes vehículos (motores) de la máquina de crecimiento local. Cita ejemplos como el de Zakopane en las montañas y Mragowo en el Distrito de los Lagos. Cabe que uno añade a varios otros ejemplos - la ciudad de Cieszyn (situada en la frontera polaca y checa) que construyó su desarrollo estratégico en torno a acontecimientos culturales (ejemplo citado en BONCZAKKuCHARCZYK et al. 1996). Si añadimos a esto la observación de que varias ciudades con una importante función turística/recreacional se encuentran entre las ciudades polacas más atractivas para los inversores externos (SWIANIEWICZ, 2002 a), llegamos a la conclusión de que el concepto reciente de CLARK de la "ciudad como una máquina de entretenimiento” (LLOYD, CLARK, 2001) tiene algo de apoyo en las políticas de los regímenes urbanos polacos.

ClaRK $(1993,2000)$ sugiere que los tipos de regímenes urbanos tradicionales como "máquinas de crecimiento" ya no son tipos de regímenes dominantes y que ahora deberíamos prestar más atención a los movimientos urbanos anti-crecimiento. ¿Podemos acaso encontrar cambios similares en los países de Europa Central y del Este? SAGAN sugiere que es muy poco probable que encontremos coaliciones anti-crecimiento en las ciudades polacas. Probablemente tenga razón en lo que se refiere a la falta de coaliciones estables e influyentes. Pero cabe también referirse a iniciativas espontáneas (aunque a veces efectivas) anti-crecimiento que aminoran la velocidad de los proyectos de crecimiento planificados o los paralizan. Las iniciativas de los pequeños comerciantes locales para parar el desarrollo -seguido por redes internacionales- de los hipermercados, los movimientos ecológicos de protesta en contra de la construcción de edificios comerciales o contra la construcción de carreteras que provocarían la tala de árboles- todos estos son solo ejemplos de dichas acciones anti-crecimiento. Un ejemplo interesante de ello nos lo proporciona el reciente conflicto relativo a la construcción de una zona residencial y de un centro comercial en el distrito de Wilanow de Varsovia. Wilanow es una parte escasamente urbanizada, y es una parte próspera de Varsovia. El plan que perseguían las autoridades locales en coalición con las empresas comerciales internacionales era construir un inmenso centro comercial e intensificar el uso del terreno en la zona residencia edificada. Sin embargo, una fuerte oposición de los residentes de Wilanow puso en duda dicho plan. En un primer momento parecía que la coalición de crecimiento podría vencer, pese a las protestas el consejo local adoptó un plan de uso de terrenos que permitía dicha construcción. Pero más allá de esto, la continua oposición llevó a una propuesta de compromiso -se redujo a 1 en vez de tres el número de hipermercados-, y se redujo asimismo de forma importante el tamaño de la construcción propuesta (WojTCZUK, 2002). Este supuesto sugiere que las coaliciones 
anti-crecimiento efectivas son posibles también en las ciudades de la ECO. También cabría mencionar algunas normativas sobre planificación en la pequeña ciudad de Podkowa Lesna (muy rica, es una ciudad pequeña a $20 \mathrm{~km}$ de Varsovia) que tenían como objetivo claro limitar el crecimiento local. Pero SAGAN tiene sin duda razón al señalar que los tipos de coaliciones máquina de crecimiento son las dominantes entre los regímenes urbanos de las ciudades polacas.

\subsection{Privatización y contratación externa de los servicios locales}

Horvath y Peteri (2002) proporcionan varios ejemplos de contratación externa y de privatización de servicios por parte de los gobiernos locales en la República Checa, Hungría, Polonia y Eslovaquia ${ }^{17}$. En Hungría, por ejemplo, el 11\% de las organizaciones que acometen con la recogida de la basura sólida, están ahora en manos privadas. En Polonia en algunos sectores de los servicios locales -tales como el mantenimiento de zonas verdes, la limpieza de las calles, y el mantenimiento de las calles- más de la mitad de las empresas que proporcionan dichos servicios son privadas (AZIEWICZ, 1998). Debería resaltarse que estos cambios orientados al mercado no vinieron impuestos por las regulaciones legales, sino que han sido una elección política independiente individual de los gobiernos locales.

Del mismo modo, la mayoría de los alcaldes está de acuerdo con la afirmación de que "el municipio debería en mayor medida adquirir servicios del sector privado, más que producirlos por su cuenta" (ver tabla 5). Dicha opinión la comparten también más frecuentemente los funcionarios de grandes ciudades que los de pequeñas comunidades.

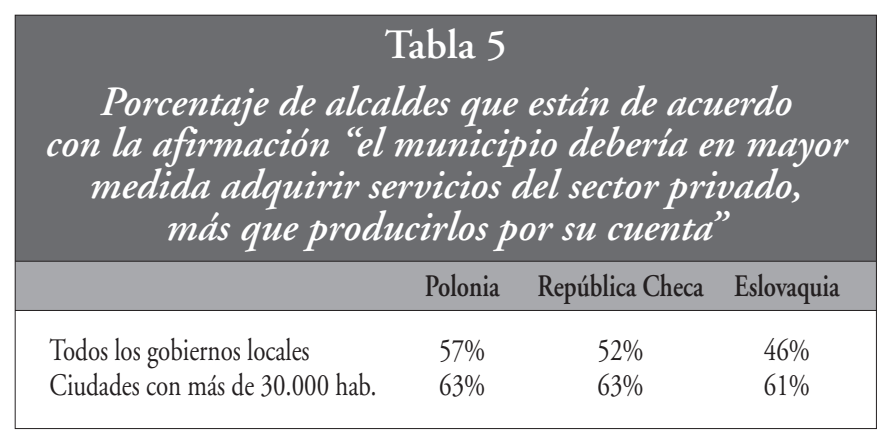

Fuente: Proyecto estudio LDI realizado en 1997.

\subsection{La creación de redes mediante la cooperación con ONG (Organizaciones no gubernamentales)}

Con anterioridad a 1990 el número de ONGs en los países ECO era muy limitado, sin embargo dicha cifra se ha disparado de forma dramática después de 1990. Soos et al. (2002) dan la información de que el número total de organizaciones del tipo ONG inscritas a finales de los años 90 era de casi 48.000 en Hungría, muy por encima de 40.000 en Polonia (ver también SiEDLECKA, 2002), 5.000 en Letonia y un número algo menor en Rumania.

Muchos gobiernos locales son cada vez más conscientes de que para alcanzar sus objetivos tienen que trabajar de forma asociada con otros actores. A nivel verbal esta afirmación probablemente sea una afirmación aceptada por la amplia mayoría de los políticos locales y los administradores, pero en la práctica las políticas que se inspiran en este tipo de planteamiento siguen siendo innovaciones escasas más que la regla general. Sin embargo, sí que existen dichas actitudes innovadores y marcan el inicio de una amplia tendencia en el futuro.

La cooperación con ONGs a la hora de proporcionar multitud de servicios vitales (fundamentalmente en las áreas de servicios sociales) requiere de una especial atención. En Polonia, el primer programa complejo de cooperación se puso en marcha en Gdynia en 1995. Entre 1993 y 1996, la proporción de ONGs que recibían apoyo de los gobiernos locales aumentó de 16\% a un 29\% (ReGULSKI, 2000). También en el caso de asociaciones en materia de construcción entre ONGs y gobiernos locales, los incentivos proporcionados por los programas extranjeros (en este caso fundamentalmente programas PHARE financiados por la Unión Europea) jugaron un papel importante (BRUD, 2002). La relación entre los dos actores está lejos de ser una relación ideal. De acuerdo con un reciente estudio (citado por BRUD, 2002) los políticos locales a menudo temen la cooperación porque:

- creen que algunas de esas ONGs compiten con organizaciones públicas tradicionales en la prestación de servicios;

- dudan de la competencia de los voluntarios y empleados de las ONGs;

- temen las complicaciones que se puedan derivar de la situación financiera inestable de muchas ONGs.

Por otro lado, los activistas de las ONGs perciben al personal de los gobiernos locales como un personal burocratizado, y no interesado en la verdadera asociación y que además no comprende los problemas específicos de las ONGs.

Pero pese a esta frecuente falta de confianza mutua, nos encontramos con ejemplos de cooperación, cada vez más a menudo. Del mismo modo, un número creciente de gestores locales esta de acuerdo con la afirmación de que la cooperación en la prestación de servicios con las ONGs trae consigo a menudo más ahorros sustanciales que los arreglos contractuales con el sector privado. En la actualidad, el 44\% de los gobiernos locales polacos contrató con ONGs para que prestaran algunos servicios locales. Es incluso más común en Hungría, donde se ha declarado la existencia de contratos con ONGs por parte de un $88 \%$ de los gobiernos locales. El 
$37 \%$ de los municipios húngaros declara haber realizado consultas con ONGs durante la toma de decisiones a nivel local. Pero ni la red de ONGs ni la frecuencia con la que cooperan están extendidas de manera uniforme por toda la región. En Letonia contratar con ONGs es mucho menos común. En Rumania ocurre incluso mucho menos a menudo por una sencilla razón y es el hecho de que no hay ONGs en el $82 \%$ de las unidades de gobierno local, mientras que en el $8 \%$ de los municipios solo hay una ONG inscrita. Por todo lo anterior no sorprende que los contratos con ONGs para algunas prestaciones de servicios sociales sean más bien excepcionales en los gobiernos locales rumanos (todas las cifras de este párrafo han sido citadas de: Soos et al., 2002).

En su análisis sobre las comunidades locales de Polonia, SAARELAINEN (2002) identifica a comités civiles organizados para apoyar las inversiones individuales con una gestión por medio de redes y muestra cómo éstas aumentan el nivel de confianza en los gobiernos locales y el nivel de participación en la toma de decisiones, etc.

\subsection{Técnicas de gestión}

Varios gobiernos locales de los países de ECO han experimentado recientemente con nuevas técnicas de gestión. Los dos siguientes constituyen ejemplos: la gestión de las finanzas locales y las técnicas de control de calidad.

En Polonia existe un número creciente de gobiernos locales que está probando métodos de elaboración del presupuesto orientados a tareas, cuentas consolidadas de ciudades utilizando instrumentos sofisticados de crédito en programas financieros que abarcan varios años, etc. (PARONSKI, 2001). También se han puesto en práctica innovaciones similares en otros países tales como la República Checa o Hungría (PigeY, 1999).

Soos (2002) nos informa de que pocos municipios húngaros han introducido ya sistemas de gestión de calidad relacionados con los certificados ISO. El mismo proceso se inicio en Polonia hace unos años. Para mediados del año 2002 había 23 municipios polacos, 5 condados y 1 región que ya habían recibido los certificados ISO 9000 o 9002, y 70 gobiernos locales ya han iniciado el proceso correspondiente para recibir certificados similares (WINDER, 2002). Tal y como citan WYsOCKI y BUCHACZ (2003), a finales del 20023 regiones (19\% de todas las regiones polacas), 8 condados (3\% de todos), 13 ciudades con más de 100.000 habitantes $(31 \%)$ y 30 pequeños municipios $(1.5 \%)$ ya habían obtenido certificados formales.

\section{5 ¿Acaso un cambio hacia gobernanza local?}

En conclusión, no existe ninguna duda de que la Nueva Gestión Pública, al igual que el cambio de gobierno local al concepto más amplio de gobernanza local atrajeron mucho a nivel local en algunos de los países de Europa Central y del Este. Sin embargo, al mismo tiempo, la mayor parte de los promotores domésticos de esta innovación no utilizan (o incluso ni siquiera conocen) los nombres de estos conceptos de moda. Un buen ejemplo de ello está en el hecho de que el término "gobernanza local" no tiene un equivalente en polaco. Dado que tradicionalmente (durante el periodo comunista) las autoridades locales tuvieron un papel formal no sólo en la prestación de servicios sino también en la planificación social y económica en general, la aceptación del nuevo papel de éstas como responsables de la riqueza en general de la comunidad local, no solo para la realización de funciones obligatorias locales, fue relativamente fácil para los concejales en los países de la $\mathrm{ECO}^{18}$.

Pero cualquier generalización breve supondría una excesiva simplificación. El único aspecto más característico de esta nueva situación ha sido la gran variación entre los distintos gobiernos locales -tanto entre países de ECO como dentro de países individuales. No debemos considerar a la región como un bloque homogéneo. La mayor parte de los ejemplos innovadores mencionados arriba se han tomado de países como Hungría, Polonia o la República Checa, mientras que en otros países como Bulgaria o Rumania (sin mencionar a las antiguas repúblicas yugoslavas, Albania o las antiguas repúblicas soviéticas) los ejemplos de cambios similares son mucho más difíciles de encontrar. Pero la situación varía también mucho de una ciudad a otra. Por un lado, ha habido líderes con una mentalidad abierta e innovadora que utilizaban técnicas de gestión modernas. Por otro lado, ha habido un número dominante de gobiernos locales que no tenían acceso ni interés por las innovaciones y que se gestionaban de una forma tradicional. El enfoque innovador es mucho más común en las grandes ciudades, pero sería simplificar demasiado reducir la variación al tamaño del gobierno local -uno puede encontrar ejemplos de pequeñas ciudades muy innovadoras o incluso de gobiernos locales rurales al igual que ejemplos de ciudades grandes muy tradicionales.

Lo que debería resaltarse es el papel del liderazgo. Los líderes fuertes y con mentalidad abierta (la mayor parte de las veces alcaldes) han sido habitualmente los motores de la innovación en la gestión de los gobiernos locales. Esto ha supuesto una fortaleza pero también una debilidad de muchas reformas locales. A menudo muchos de los cambios por el/la líder sin el suficiente apoyo (o a menudo si el suficiente entendimiento de la situación) del resto de los políticos locales y del personal. Por tanto, el cambio en la posición que ocupa el alcalde puede en algunos casos suponer el fin de las innovaciones y la vuelta a métodos tradicionales de gestión. Dicha situación ha sido especialmente frecuente en el caso de pequeños gobiernos locales, en los que la cantidad de personal cualificado ha sido muy limitado.

También el estudio de GASPAR/WRIGHT de la cultura organizativa en cuatro de las ciudades de tamaño mediano de Hungría 
(1996), apoya parte del escepticismo con respecto a la tendencia a la gobernanza en los países de la ECO. Notaron en ocasiones una distancia significativa entre utilizar "etiquetas de moda" e implementar realmente las políticas o entre valores declarados y valores reales. Denominan a este fenómeno "vestir la ventana" que en ocasiones puede llevar al observador a una "ilusión cultural"

El desarrollo de la Nueva Gestión Pública relacionado con las innovaciones no se ha destacado de forma unívoca por todos los observadores. VERHEIJEN (sin fecha), centrándose en las reformas administrativas en el nivel central, sugiere que las técnicas de gestión en la Nueva Gestión Pública pueden tener un efecto negativo en los países de la ECO. Identifica la Nueva Gestión Pública con la creación de agencias semi-independientes y señala problemas de responsabilidad. Dice que pueden habitualmente resolverse en la Europa Occidental, pero con mayores dificultades en los países de la ECO. Teniendo en cuenta este aviso, deberíamos resaltar que la creación de agencias semi-independientes en la región ECO es una enfermedad existente más a nivel central que a nivel local, aunque podemos encontrar ejemplos que apoyan lo que defiende VERHEIJEN también en el contexto de un ámbito en desarrollo de la gobernanza local.

Pero cualquiera que sea nuestra evaluación de los recientes cambios, no resulta difícil predecir que el progreso de la integración europea fortalecerá estas tendencias hacia nuevas técnicas de gestión y nuevas estructuras de gobernanza en general a nivel local.

\section{Conclusiones}

El tamaño de este trabajo, al igual que la cantidad de datos ya recopilados en varios estudios empíricos, no nos permiten dar una respuesta completa y comprensiva de las cuestiones formuladas al inicio del mismo. Con respecto a muchos de los aspectos mencionados sólo podemos presentar hipótesis basadas en un conocimiento general de la situación más que pruebas contundentes basadas en una investigación empírica sólida. Sin embargo, podemos formular algunas conclusiones generales.
Pese a las raíces históricas comunes, la evolución de las reformas descentralizadoras y la democracia local en la Europa Central y del Este no va en una dirección única uniforme. No existe definitivamente ningún modelo separado de gobierno local común de Europa Central y del Este para la mayor parte de los países de la región. El sistema todavía se está formando, pero parece que algunos de los países evolucionan hacia un modelo cercano al modelo descrito en la literatura como modelo del norte de Europa o modelo de norte y centro Europa (Polonia, Estonia), mientras que otros se aproximan más al modelo del sur de Europa (Napoleónico) (Eslovaquia, Rumania, quizás Bulgaria). Esto no significa que no haya aspectos específicos del sistema de gobierno local en los países de ECO que lo distinguen de las democracias locales en Europa Occidental. Pero estas características específicas no permiten identificar a un tipo de gobierno local separado ni permiten rechazar la hipótesis de una convergencia gradual con dos modelos identificados en la Europa Occidental con anterioridad.

También queda claro que los políticos locales de al menos algunos de los países de la ECO (Polonia, Hungría, la República Checa) se ha visto atraídos por la idea de cambiar un gobierno tradicional por un concepto más amplio de gobernanza y por estilos de gestión que a menudo se identifican con la Nueva Gestión Pública. El papel de los contactos internacionales y de los consultores extranjeros presentes en las ciudades de la ECO durante los años 90 tuvo un impacto significativo en dicho desarrollo. Al mismo tiempo, la mayor parte de estos líderes no utilizan (o incluso ni siquiera conocen) etiquetas tales como "Nueva Gestión Pública" o "gobernanza local" (en la lengua polaca no existe ni siquiera un término equivalente para "gobernanza local"). La realidad social y económica de la región hace que las condiciones para la implementación práctica de las políticas de "gobernanza local" sean diferentes de aquellas condiciones existentes en Europa Occidental. Se pueden mencionar por ejemplo los recursos limitados que están en manos de empresarios locales, la relativa debilidad de las ONGs, el mercado limitado de prestadores de servicios que podrían contratarse externamente etc.

Uno puede esperar que, junto con los procesos de integración europea, las tendencias de adaptación y la convergencia en la región se fortalezcan. 
Artículo traducido por Cristina Alba MuÑoz.

${ }^{1}$ El autor es profesor en el Centro de Estudios Europeos Regionales y Locales (EUROREG), Universidad de Varsovia, Polonia

2 Bulgaria, República Checa, Estonia, Hungría, Letonia, Lituania, Polonia, Rumania, Eslovaquia, Eslovenia.

3 Por ejemplo, STOKER (1991) apunta que el establecimiento de un gobierno local viable en Europa del Este es esencial para el establecimiento y mantenimiento de un proceso democrático (p.1), pero este libro no incluye ningún otro tipo de análisis en mayor profundidad de cualesquiera países distintos de los miembros de la Unión Europea. Austria.

${ }^{4}$ Dado que se centran en Estados unitarios dejan a un lado a Alemania, Suiza y

5 En su análisis JoHn se centra en el modelo PAGE/Goldsmith. Pero el modelo de SHARPE/HeSSE muestra multitud de similitudes y proporciona comentarios complementarios.

6 Para más sobre cambios en la organización territorial y debates actuales en los países de ECO, ver SWIANIEWICZ, 2002c.

7 Siguiendo la terminología de SHARPE (1993: 1) hablo de este meso level para describir "el nivel intermedio de gobierno entre el centro y el nivel básico municipal o comunal". Dicho nivel puede adoptar la forma de nivel regional o por tipo condado del gobierno.

8 El mejor indicador de la descentralización funcional parece estar en el porcentaje del gasto público total que corresponde a los autogobiernos sub-nacionales, pero este indicador crea ciertos problemas metodológicos y de datos debido a la existencia de varios fondos públicos extrapresupuestarios en varios países. Por tanto, nos centramos en un indicador menos perfecto pero más claro: el porcentaje de gasto sub-municipal en relación con el PIB

${ }^{9}$ Con anterioridad a 1994 los alcaldes húngaros de pequeños pueblos ( por debajo de los 10.000 habitantes) eran elegidos por los ciudadanos, mientras que en las ciudades de mayor tamaño se nombraban por el consejo.

${ }^{10}$ La elección directa de alcaldes es también popular en otros países de la región ECO ( que no analizamos en este capítulo) tales como Albania, Ucrania, Rusia, etc.

${ }^{11}$ Los comentarios expuestos en esta y en la siguiente sección se basan en gran medida en la experiencia polaca y en menor medida en ejemplos obtenidos de la República Checa, Hungría y Eslovaquia. Lamentablemente, mi conocimiento es insuficiente para proporcionar un análisis de estos aspectos en los gobiernos locales que operan en los estados Bálticos, Rumania o Bulgaria. Sin embargo, la información disponible sugiere, que los cambios en los estilos de gestión han sido los más pronunciados en los cuatro países que trato de incluir en mi análisis.

12 ILLNER ( 2002) y Soos (2002) formulan una opinión similar basándose en las experiencias checa y húngara.

13 Por ejemplo, las ideas de la Nueva Gestión Pública se han discutido ampliamente por los políticos locales polacos y por el personal alto directivo. Es así indicativo que el famoso libro de OSBORNE y GABLER, Reinventing government se tradujera al polaco por uno de los anteriores altos directivos de la ciudad de Gdansk. También resulta característico que uno de los conocidos políticos locales progresistas- anteriormente alcalde vice-ejecutivo de la ciudad de Cracovia- haya estado promocionando en sus discursos por toda Polonia la idea de que gestionar una ciudad es lo mismo que gestionar una gran empresa. Por último, merece la pena mencionar que la expresión "Nueva Gestión Pública" se refiere directamente al programa actual de formación para la administración local, que patrocina el Banco Mundial y se está implementando a través del Ministerio polaco responsable de la administración pública (POTKANSKI, 2002).

${ }^{14}$ El estudio fue parte de un proyecto de investigación internacional llamado "Democracia Local e Innovación (LDI) coordinado por la Universidad de Bergen y patrocinado por los gobiernos noruegos.

15 Sin embargo, deberíamos añadir que pese a las preferencias políticas expresadas por los políticos locales, existe una gran distancia entre la percepción de los funcionarios locales y la percepción de los empresarios locales con respecto al impacto que las autoridades locales tienen en el desarrollo económico. Sólo el 4\% de los empresarios locales en Polonia ven buenos resultados en las políticas económicas locales, el $13 \%$ ve esfuerzos pero sin claros resultados, mientras que el $61 \%$ no aprecian ningún tipo de actividades de los gobiernos locales dirigidas a estimular el desarrollo económico local (SWIANIEWICZ, 2002 a).

16 Los alcaldes, altos funcionarios, concejales, ciudadanos, todos ellos entrevistados en la República Checa, Hungría, Polonia y Eslovaquia.

17 Horvath/Peteri (2002) proporcionan también ejemplos de iniciativas de asociaciones publico-privadas en los gobiernos locales de ECO.

18 Aunque no debemos olvidar que los instrumentos utilizados para dirigir las economías con anterioridad a 1990 era drásticamente diferentes de los instrumentos contemporáneos utilizados para influenciar el desarrollo económico local.

\section{Bibliografia}

AzIEWICZ T. (1998) Gospodarka rynkowa w ustugach komunalnych, The Gdansk Institute for Market Economics, Gdansk.

Baldersheim H., M. Illner, A. Offerdal, L. Rose, P. Swianiewicz (eds.) (1996) Local Democracy and the Process of Transformation in East-Central Europe, Westview, Boulder.

BoncZak-KucharczyK E., L. Cousins, K. Herbst, M. Stewart (1996) Lokalne strategie rozwoju gospodarczego, Brytyjski Fundusz Know-How - Fundusz Wspó?pracy, Warszawa.

Coulson A (ed.) (1995) Local Government in Eastern Europe, Edward Elgar, Aldershot.

Caufield J. (2002) "Local Government Finance in OECD Countries" [in:] J. Caufield, H. Larsen (eds.) Local Government at the Millenium, Leske + Budrich, Opladen.
Clark T.N. (1993) "Local Democracy and Innovation in Eastern Europe", Environment and Planning: Government and Policy, Vol. 11, p. 171-198.

Clark T.N. (2000) "Old and New Paradigms for Urban Research", Urban Affairs Review, Vol. 36, No. 1, p. 3-45.

Gaspar M., Wright G. (1996) "Organisational Culture Barriers of Local Government Management Development: The Hungarian Experience” [in:] J. Jabes (ed.) Developing Organizations and Changing Attitudes: Public Administration in Central and Eastern Europe, NISPAcee, Bratislava.

Hambleton R. (1998) "Competition and Contracting in UK Local Government" [in:] N. Oatley (ed.) Cities, Economic Competition and Urban Policy, Paul Chapman, London.

Hambleton R. (2001) "The new city management" [in:] R. Hambleton, H. Savitch, M. Stewart (eds.) Globalism and local democracy, Palgrave, London. 
HeSSE J.J., L.J. ShARPE (1991) "Local Government in International Perspective: Some Comparative Observations" [in:] J.J. Hesse (ed.) Local Government and Urban Affairs in International Perspective, Nomos Verlagsgesellschaft, Baden-Baden.

Horvath T. (ed.) (2000) Decentralisation: Experiments and Reforms, Open Society Institute, Local Government Initiative, Budapest.

Horvath T., G. Peteri (2001) Navigation to the Market: Regulation and Competition in Local Utilities in Central and Eastern Europe, Open Society Institute, Budapest.

ILLNER M. (2002) "Thirteen Years of Reforming Subnational Government in the Czech Republic", paper prepared for the Joint Conference of IPSA's RC05 and the German Political Science Association Workgroup "Reforming Local Government: Closing the Gap Between Democracy and Efficiency" Stuttgart, September 26-27, 2002.

"Improvement of Administrative-Territorial Division" (2003), Albanian Ministry for Local Government and Decentralisation, Tirana.

John P. (2001) Local Governance in Western Europe, Sage, Londyn-Thousand Oaks-New Delhi.

JurLina-Alibegovic D. (2002) The Model of Local Government Financing in Croatia, Croatian Law Centre, Zagreb.

Kandeva E. (ed.) (2001) Stabilisation of Local Governments, Open Society Institute, Local Government Initiative, Budapest.

KulESZA M. (2002), "Methods and Techniques of Managing Decentralisation Reforms in CEE Countries: The Polish Experience" [in:] Peteri G. (ed.): Mastering Decentralisation and Public Administration Reforms in Central and Eastern Europe, Open Society Institute, Local Government Initiative, Budapest.

LARSEN H. (2002) "Directly Elected Mayors: Democratic Renewal or Constitutional Confusion?" [in:] J. Caulfield, H. Larsen (eds.) Local Government at the Millenium, Leske + Budrich, Opladen

LEACH S., WiLSON D. (2000) Local Political Leadership, The Policy Press, Bristol.

Local Finance in the Fifteen Countries of the European Union, Dexia, Paris, 2001.

Lloyd R., T.N. Clark (2001) "The City as an Entertainment Machine" [in:] K.F. Gotham (ed.) Critical Perspectives on Urban Redevelopment, Research in Urban Sociology, Vol. 6 , JAI Press/Elsevier, Oxford.

MaenpaA O. (2002) Report on Administrative Decentralization in Macedonia, unpublished report for the Council of Europe.

Marcou G. (ed.) (2002) Regionalisation for Development and Accession to the European Union, Open Society Institute, Budapest.

Mouritzen P.E., Svara J.H. (2002) Leadership at the Apex, University of Pittsburgh Press. London.

Newton K., T.J. KarRan (1985) The politics of local expenditure, Macmillan,

Page E.C., M. Goldsmith (ed.) (1987) Central-Local Government Relations: A Comparative Analysis of West European Unitary States, Sage, London. Warszawa.

PAKONSKI K. (2001) Zintegrowane zarzadzanie finansowe, Municipium,

Peteri G., V. Zentai (2002) “Lessons on Successful Reform Management" [in:] G. Peteri (ed.) Mastering Decentralization and Public Administration Reforms in Central and Eastern Europe, Open Society Institute, Budapest.

PIGEY J. (1999) Fiscal Decentralisation and Local Government Finance in Hungary, Urban Institute, Washington.

POTKANSKI T. (2002) "Systemy zarzadzania jako?ci? a rozwój instytucjonalny jednostek samorzadu terytorialnego", unpublished material of the Ministry of Interior and Public Administration, Warszawa.
RegUlSKI J. (1999) Building Local Democracy in Poland, LGI Discussion paper No. 9, Open Society Institute, Budapest.

SaArelainen T. (2002) "Can Network Management Improve Local Management and Governnance?”, NISPACee Occasional Papers, Vol. 3, No. 2.

SaGan I. (2000) Miasto: scena konfliktów i wspónpracy, Gdansk University.

SiedleCKA E. (2002) "Spoleczenstwo malo obywatelskie", Gazeta Wyborcza, 23.09.2002

"The Size of Municipalities, Efficiency and Citizen Participation" (1995), Local and Regional Authorities in Europe No. 56, Council of Europe, Strasbourg.

Sharpe L.J. (ed.) (1993) The Rise of Meso Government in Europe, Sage, LondonNewbury Park-New Delhi.

Soos G. (2002) "Local Government Reforms and the Capacity for Local Governance in Hungary", paper prepared for the Joint Conference of IPSA's RC05 and the German Political Science Association Workgroup "Reforming Local Government: Closing the Gap Between Democracy and Efficiency" Stuttgart, September 26-27, 2002.

Soos G., G. ToKA, G. Wright (eds.) (2002) The State of Local Democracy in Central Europe, Open Society Institute, Budapest.

StOKER G. (1991) "Introduction: Trends in Western European Local Government" [in:] R. Batley, G. Stoker (eds.) Local Government in Europe: Trends and Developments, St. Martin Press, New York.

SWIANIEWICZ P. (ed.) (2001) Public Perception of Local Governments in Central and Eastern Europe, Open Society Institute, Budapest.

SWIANIEWICZ P. (2002a) "The Investment Attractiveness of Polish Cities", paper prepared for the EURA Conference in Turin, 18-20 April 2002.

SWIANIEWICZ P. (2002b) "Reforming Local Government in Poland: Top-Down and Bottom-Up Processes", paper prepared for the Joint Conference of IPSA's RC05 and the German Political Science Association Workgroup "Reforming Local Government: Closing the Gap Between Democracy and Efficiency" Stuttgart, September 26-27, 2002.

SWIANIEWICZ P. (ed.) (2002c) Consolidation or Fragmentation? The Size of Local Governments in Central and Eastern Europe, Open Society Institute, Budapest.

SwianiewiCZ P. (2002d) "Partisan Cleavages in Local Governments in Poland After 1990", paper presented on the conference on "Regionalisation of Polish Politics", School of Slavonic and East European Studies, University of Central London, April 18-20.

SWIANIEWICZ P. (2003) "The Values of Local Democracy as Seen by Mayors in East-Central Europe" [in:] H. Baldersheim, M. Illner, H. Wollmann (eds.) Local Democracy in Post-Communist Europe, Urban Research International Series, Leske/Budrich, Opladen.

SWIANIEWICZ P., KLimsKa U. (2003) "Czy wielkie miasta sa sterowalne? Wplyw sytuacji politycznej na warunki zarzadzania najwiekszymi miastami Polski”, Samorz?d Terytorialny No. 3.

Verhejen T. "Redefining Accountability Systems in Public Management; A Challenge for Central and East European Reformers".

WinDER I. (2002) "Zarzadzanie jakoacia w administracji: normy ISO 9000", Gazeta Samorzsdu i Administracji, No. 13.

Wojtczuk M. (2002) "Przesadzone: Auchan powstanie", Gazeta Stoleczna 08.10.2002.

Wysocki S., BuchaCz T. (2003) „Zarzadzanie jakoscia w administracji”, Stuzba Cywilna No. 5 (Autumn 2002-Winter 2003). 